Regina Silveira *

\title{
Prazer da Imagem
}

Regina Silveira é artista multimídia, gravadora, pintora, professora. Conclui, em 1959, bacharelado em pintura no Instituto de Artes da Universidade Federal do Rio Grande do Sul (IA/UFGRS), onde estuda com Aldo Locatelli (1915-1962) e Ado Malagoli (1906-1994), entre outros. Licencia-se em desenho pela Faculdade de Filosofia da Pontifícia Universidade Católica do Rio Grande do Sul (PUCRS). No início da década de 1960, tem aulas de pintura com Iberê Camargo (1914-1994), e de gravura com Francisco Stockinger (1919-2009) e Marcelo Grassmann (19252013), no Ateliê Livre da Prefeitura Municipal de Porto Alegre. Como bolsista do Instituto de Cultura Hispânica, em 1967, estuda na Faculdade de Filosofia e Letras de Madri. Em 1969, é convidada a ministrar cursos na Faculdade de Artes e Ciências da Universidade de Porto Rico. Volta para o Brasil em 1973, e coordena até 1985 o setor de gravura da Faculdade de
Resumo Nesta comunicação a artista Regina Silveira seleciona obras específicas de seu próprio percurso que possam ter buscado deliberadamente provocar no destinatário efeitos de prazer, surpresa ou fruição, e que estão certamente ligados às funções da arte, aquelas capazes de transformar a percepção e a experiência do real.

Palavras chave Arte Contemporânea, Instalação, Arte e Tecnologia, Imagem.

\section{Pleasure of the Image}

Abstract In this communication, artist Regina Silveira selects among her specific works that may have deliberately sought to cause in the public effects of pleasure, surprise or enjoyment, and which are certainly linked to the functions of art, those capable of transforming the perception and experience of reality.

Keywords Contemporary art, Installation, Art and Technology, Image. 
Artes Plásticas da Fundação Armando Álvares Penteado (Faap). Em 1974, passa a lecionar na Escola de Comunicações e Artes da Universidade de São Paulo (ECA/ USP). Na mesma instituição, defende dissertação de mestrado em 1980 e, em 1984, obtém o título de doutora. De 1991 a 1994, permanece em Nova York, com bolsas de estudo concedidas pela John Simon Guggnheim Foundation (1991), pela Pollock-Krasner Foundation (1993) e pela Fullbright Foundation (1994). Em 1995, recebe bolsa de artista residente da Civitella Ranieri Foundation. Recebe, em 2000, o Prêmio Cultural Sergio Motta. Lista de inúmeros prêmios e participações em grandes mostras e bienais e faz parte de várias coleções no Brasil e exterior, sendo uma das mais importantes artistas contemporâneas brasileiras.
Tendo recebido a missão de vir aqui para falar do Prazer da Imagem, na trilha deste pequeno e notável texto de Roland Barthes (Prazer do Texto - R. Barthes) que foca a recepção/ fruição quase sensual, de escrituras abertas a esta dimensão do prazer (o que alguém já considerou ser o estado da linguagem quando vira arte) mas com base em minha própria obra, decidi fazer escolhas específicas em meu percurso, para selecionar obras que possam ter buscado deliberadamente provocar no destinatário esses efeitos de prazer, surpresa ou fruição, e que estão certamente ligados às funções da arte que mais prezo, aquelas capazes de transformar a percepção e a experiência do real.

Entretanto, tomando posição quanto ao papel do interprete, já declaro que não tenho em meu percurso obras tão abertas que na própria concepção tenham deixado intervalos para um significado que só se completa pela interação - muitas vezes até ativa, em termos quase físicos com o espectador.

Estou (ou pelo menos quero estar) mais próxima às conceituações de Duchamp sobre o papel do espectador, com interpretações ambíguas e abertas onde se empilham os significados - na rota dos textos prazerosos de Barthes - aqueles longe da lógica e das classificações seguras.

Dentro de minha produção de tantas décadas, poderia ter escolhido falar das obras e exposições das que pude derivar atividades educativas, desenvolvidas em colaboração com museus e instituições, no Brasil e no exterior. Certamente temas e imagens envolvidos puderam produzir efeitos transformadores nos públicos de diversas idades convocados a estas espécies de diálogos e repostas. Mas essas atividades foram quase todas feitas ao abrigo de instituições e espaços de arte.

Por isso também minha escolha hoje foi outra, apoiada na crença firme de que as obras que respondem mais ativamente à função de transformar a percepção e a experiência do real, são aquelas que fiz em espaços públicos, fora dos espaços protegidos da arte onde tratei de inscrevê-las nos espaços sociais, da vida. Paradoxalmente, nas condições em que é mais difícil aferir aquilo que se deseja apontar aqui : os efeitos transformadores sobre usuários, recebedores, ou como se puder chamar o público anônimo que representa o lado da recepção da arte, nas ruas, nos territórios da arte pública.

Ainda algumas observações: que tipo de percepção? Aquela do corpo a corpo com o fenômeno, não a mediatizada digitalmente... isto seria outra discussão... Não sei se seus efeitos são exatamente prazerosos, como autora só posso falar do que moveu minhas intenções, e nas estratégias e operações poéticas em que me apoio. Tenho afirmado e mesmo já se sabe que meu instrumento preferido tem sido a produção de deslocamentos do sentido, tendo como meta a descontextualização de significados já instalados (ostranenie). Tenho sempre presente (uma espécie de norte?) a observação de Villem Flusser sobre o papel do artista na vida, no real papel de mágico, que faz a conexão mágica com o mundo. Para enxertar o inusual, o surpreendente, a estranheza - apostando na capacidade de mudar tudo. Gosto de pensar que a missão pode ser essa... 
Minha apresentação (finalmente!) então é sobre a fatia de Arte Pública do meu trabalho. Através de alguns exemplos (que não esgotam a quantidade), repartidos inicialmente numa divisão já conhecida - efêmera/permanente.

Começo pelas obras que tem como traço principal a efemeridade, o que abrange a grande maioria desta minha produção. As mais radicais foram as que se aproximaram das fantasmagorias que por décadas habitaram minhas reflexões no campo das sombras perspectivadas, anamorfoses, das determinações dos pontos de vista e sobretudo dos truques óticos- em suma, da tradição ilusionista inteira, vista criticamente, num percurso que de saída interroga o real visual e que me levou à fotografia, depois ao pré-cinema, às simulações digitais, e recentemente até a VR....

Minha estreia nesta classe de aparições foi o Super Herói, Night and Day, um tipo de fantasma que teve como primeiro habitat a Avenida Paulista (em 1997) - a versão Day é a sombra esticada de $42 \mathrm{~m}$ colocada sobre uma fachada da avenida, sempre à vista-- e a versão Night foi a animação com raio laser, de uma imagem que movia apenas a capa, e que podia cruzar uma distancia de $10 \mathrm{~km}$, sempre em foco. Com um equipamento então gigante (para resfriamento do canhão de laser) colocado no terraço do Conjunto Nacional, o super herói percorreu a avenida durante cinco noites seguidas. $\mathrm{O}$ efeito foi forte (encontrei anos depois quem me contasse a história de ter visto este herói-aparição, desde dentro de um ônibus, sem saber que falava com a autora) e também foi forte e interessante o anonimato (tanto meu quanto do público). Depois o Super Herói circulou em Buenos Aires, em Puerto Rico - mas em sua última aparição teve que ficar preso à fachada do edifício do Itaú Cultural, pela atual regulamentação das projeções urbanas.

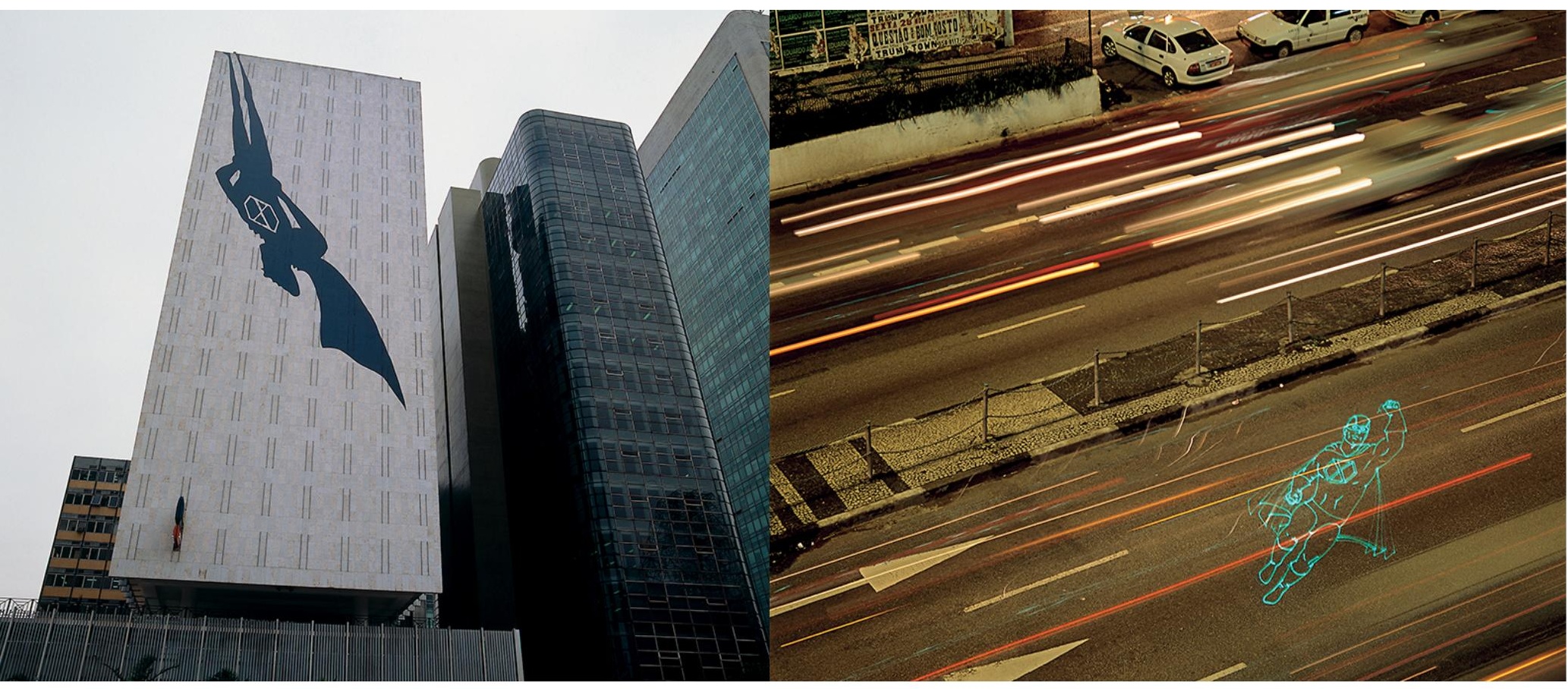

Fig 1. Super Herói, Night and Day (1997) 
Então veio a mosca de Transit (2001) - solucionada como gobo metálico projetado a partir de um veiculo em deslocamento, por diversas noites e em diferentes áreas da cidade - o que gerou o documentário Transit (Olhar Periférico Filmes). A mosca transitou pela Paulista, pelo centro da cidade, Minhocão, a Oca no Ibirapuera, Obelisco, Memorial da América Latina - e muitos outros lugares onde sua presença não era exatamente um signo de prestigio...

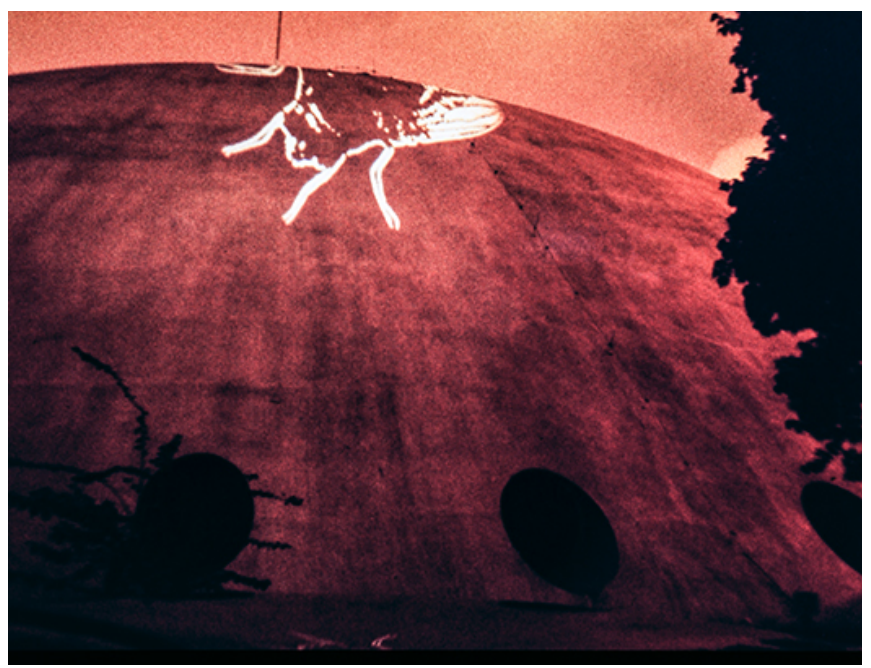

Fig 2. Transit (2001)

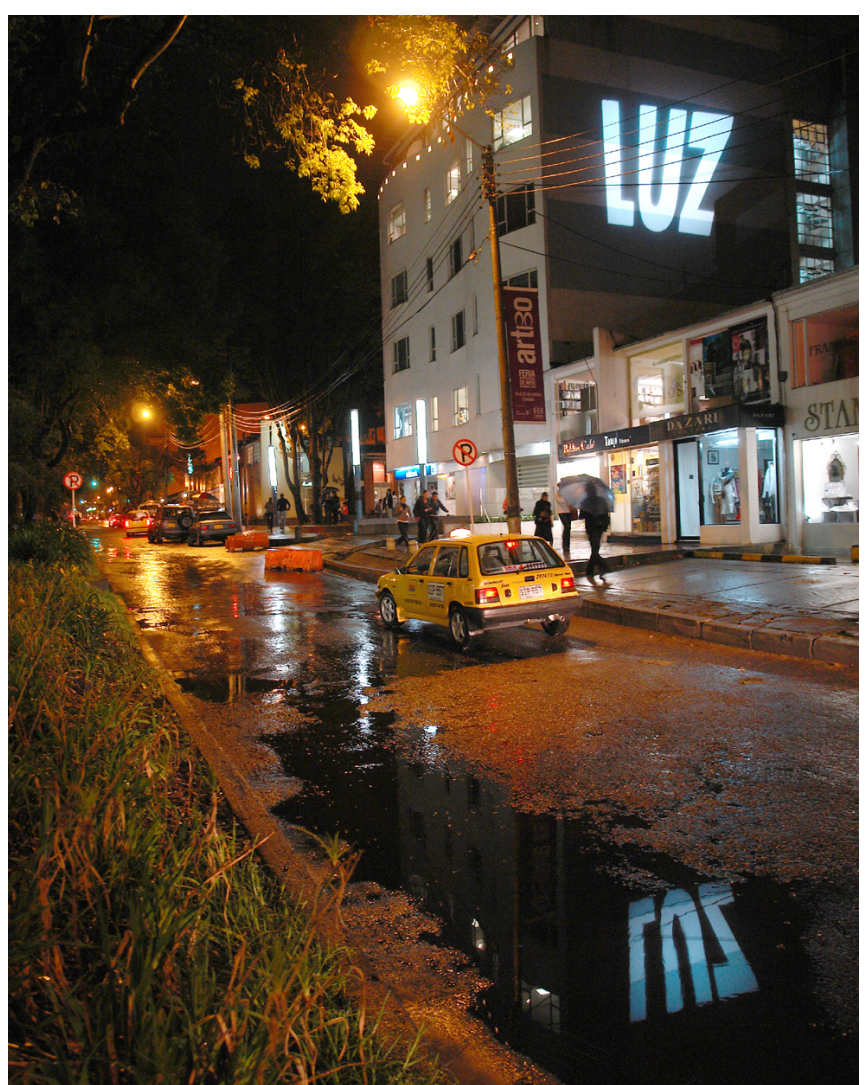

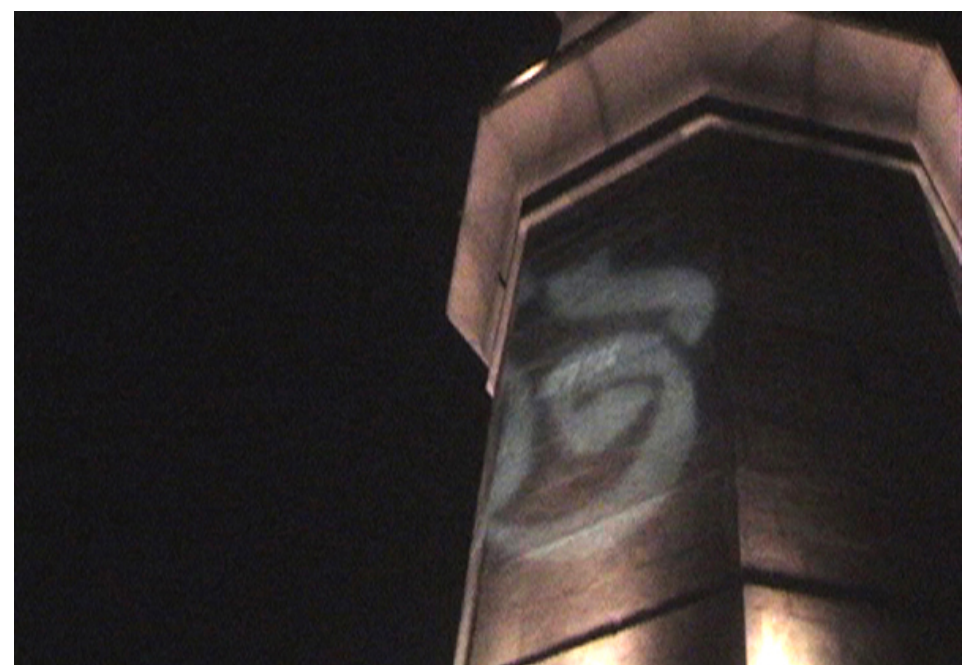

Fig 3. NOOR (2005)

Uma projeção peculiar foi NOOR (2005), a caligrafia hindi para a palavra LUZ/Noor que circulou nos mercados noturnos durante festival de Performing Arts, 2006, em Lahore, Paquistão (com participação indicada pelo Ministério de Relações Exteriores do Brasil), cidade onde estive ministrando o workshop Vestígios na Fac. de Arte e Design Noor, foi um tipo de provocação/homenagem a Nur Jahan, imperatriz da Índia e Paquistão (sec. 18), uma das heroínas da Ásia, poetisa e feminista avant la lettre, numa operação arquitetada em cumplicidade com o então embaixador Fausto Godoy, assessorada por um poeta caligrafo paquistanês e algumas alunas mulheres do meu workshop. (Os meninos não podiam se envolver....)

Dela derivou a projeção Iluminaluz (2007) da palavra LUZ, uma tautologia luz palavra/iluminada ambulante, em Bogotá.

Fig 4. Iluminaluz (2007) 


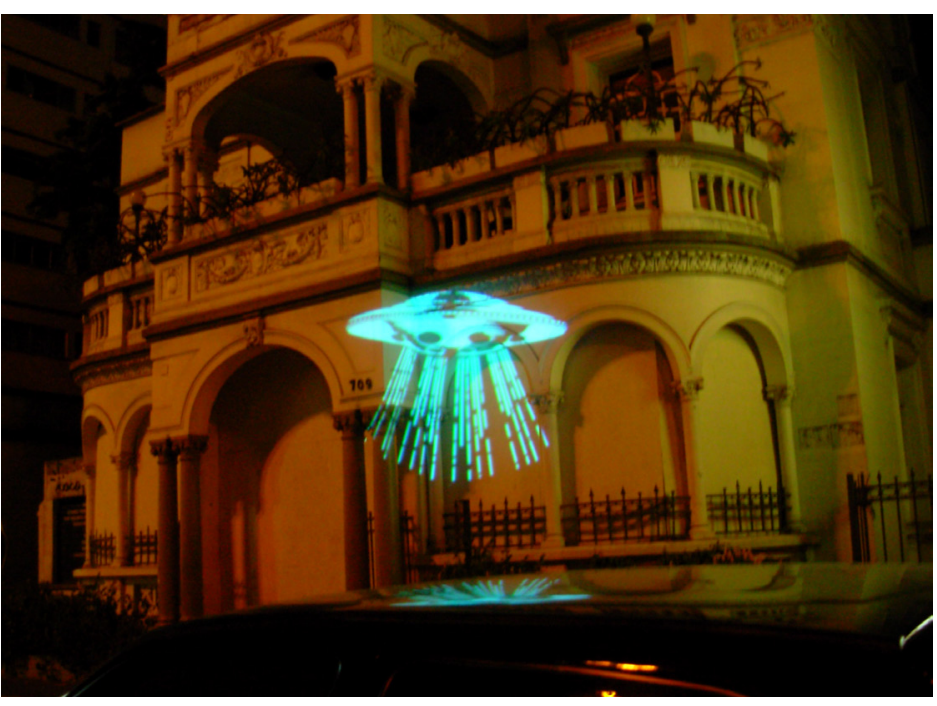

Fig 5. UFO (2006)

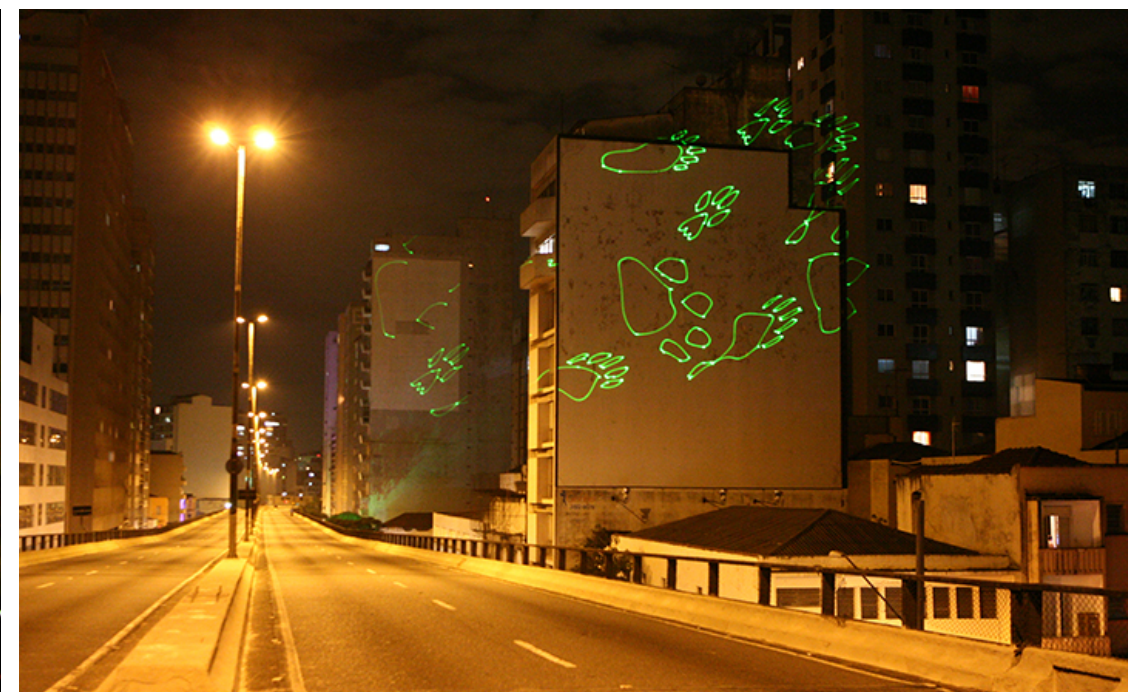

Fig 6. Passeio Selvagem (2009)

Na sequência de personagens noturnos, ainda cito o UFO (2006) - que circulou em SP em noite de Virada Cultural - e a animação a laser Passeio Selvagem (2009), vista originalmente em Sevilha por ocasião de um evento que reunia manifestações de pré-cinema, e no centro de SP - Copan e Minhocão, por uma noite.

Minha mais recente aparição no tecido urbano foi outra mosca: Surveillance (2015) a animação digital em 3D que projetei publicamente no festival Visualismo, na Praça Mauá, no Rio - no MAR e sobre os edifícios do jornal A Noite...

Como autora, meu maior prazer em qualquer dessas intervenções foi a de me misturar com o público e compartilhar as suas reações.... Mas não sei se, no lugar, saberia criar distância para avaliar essas reações sempre difusas e anônimas ....

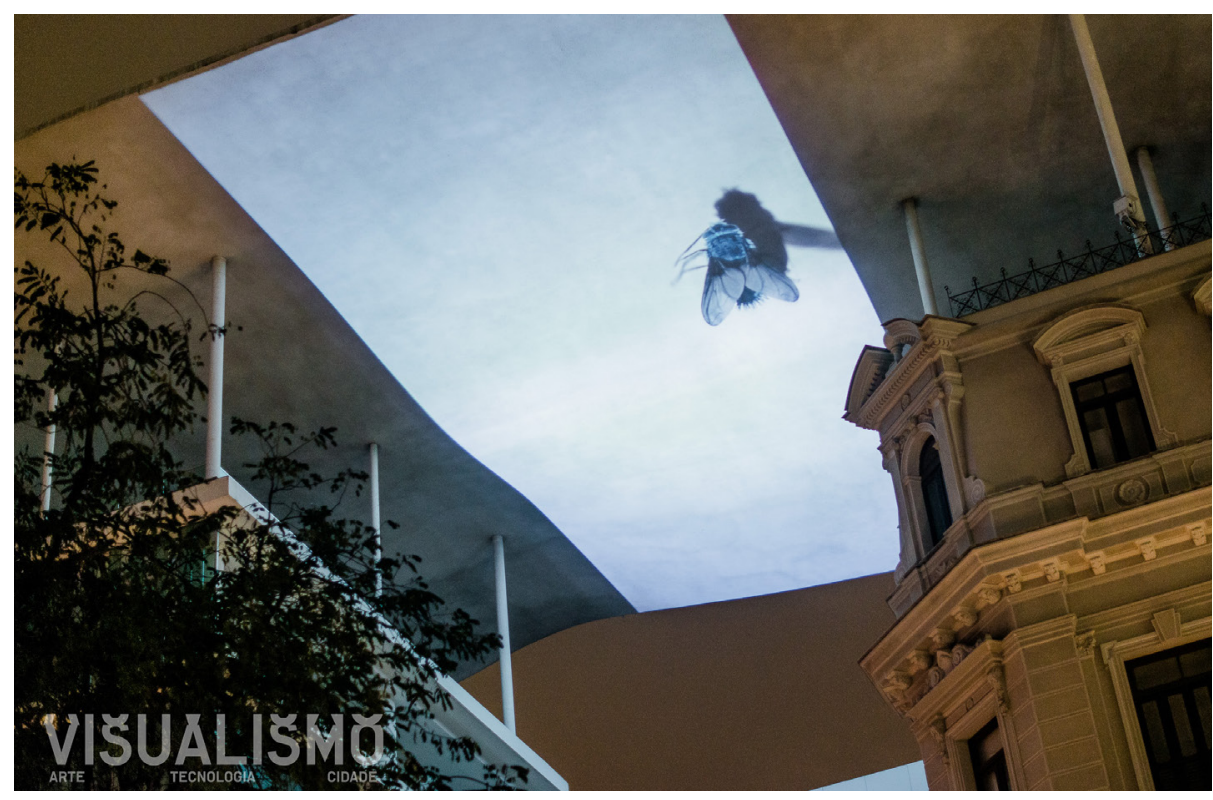



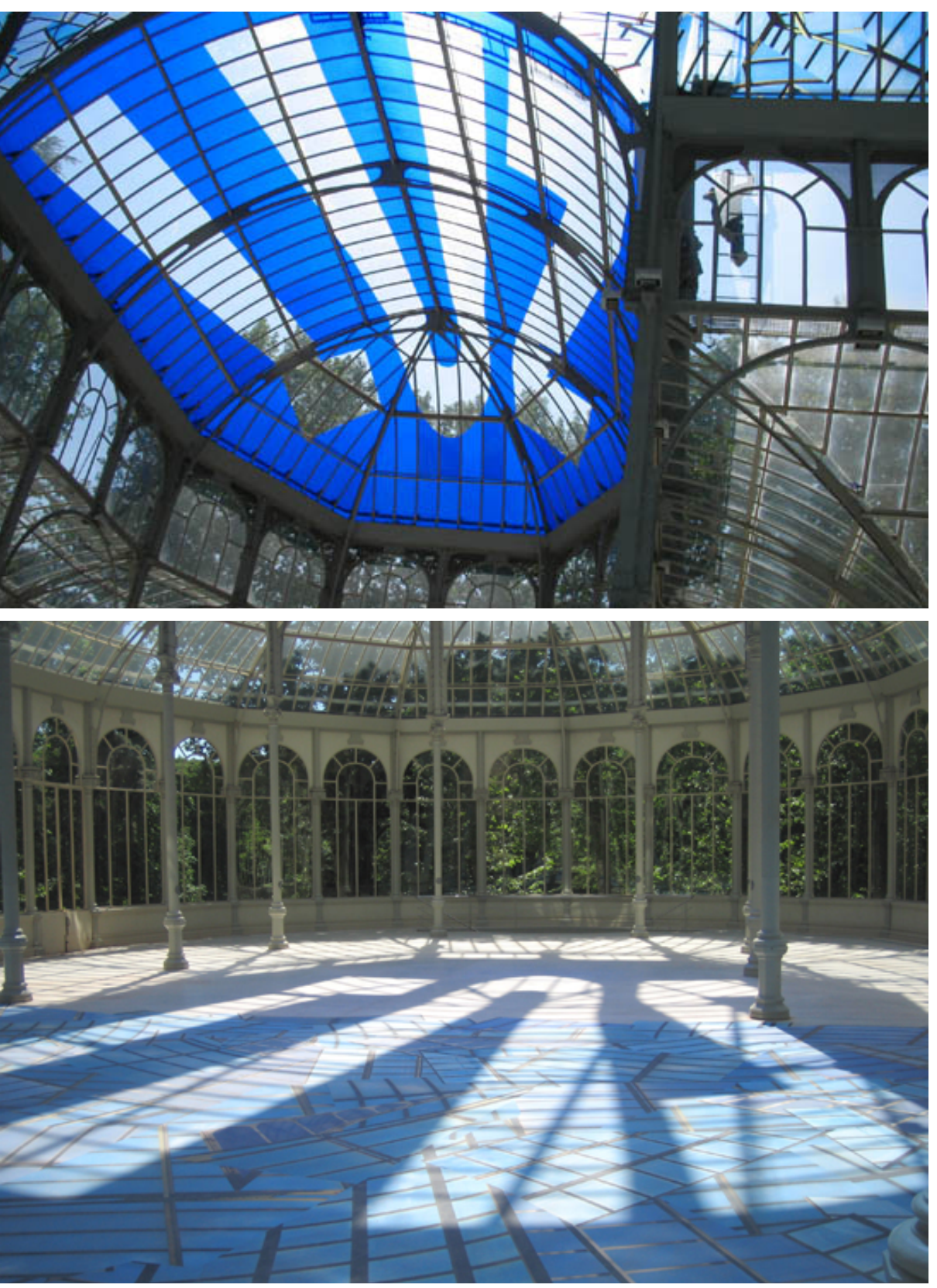

Fig 8. LUMEN (Madrid 2005)

Fig 9. LUMINATO (Toronto 2015)
Depois dos fantasmas iluminados, ainda na categoria de obras publicas efêmeras tenho diversas obras que são fixas e se prendem a arquiteturas ou espaços de convívio, no contexto urbano. Há o grupo das obras ligadas a visualidades que tentam transmitir significados de maravilhamento e transcendência, descendentes da minha exposição intervenção LUMEN - no Palácio de Cristal (Madrid 2005) como os Glossários, que tem funcionado como constelações luminosas da palavra LUZ. O primeiro deles foi o Glossário - que construí no lobby de um dos prédios do Hospital Paulo Vasconcellos (2010) seguido de outros como o Glossário refletido no chão do pátio interno do Museu Lasar Segall (2011) e o conjunto de marquises iluminadas, o Glossary que fiz em colaboração com o arquiteto Álvaro Razuk - como obra efêmera e especifica para o festival LUMINATO em Toronto (2015) - todos com forte acentuação no efeito (deliberado) de beleza e prazer no uso e interpretação da imagem. 0 de mais curta duração foi o último, pois o festival (música e performance) durou apenas 10 dias... 
Entre as obras efêmeras fixadas em espaços urbanos Phantasmata - que realizei para a Bienal de Havana em 2015 - propõe um viés mais crítico. Phantasmata é um grafitti pintado sobre o asfalto, feito parcialmente no Malecon e integralmente na frente do Palácio de la Revolución, em Havana. Trata-se da imagem agigantada (diagramática) de um estacionamento fantasma, onde alinhei ícones de veículos supostamente estacionados - entendendo como veiculo tudo o que se move ou desloca, em terra, mar ou arseja mecânico ou animal - na verdade a imagem postulava o que já estava em tempo de estacionar em Cuba - o barco, a cucaracha, o tanque de guerra, o míssil etc. Para esta realização arrolei um bando de jovens colaboradores - primeiro deles foi o Magosh, grafiteiro paulistano da melhor estirpe da arte da rua, que passou os meses anteriores à minha ida a Havana em meu estúdio ensinando e fazendo as máscaras que depois foram finalizadas no workshop com os alunos da ISDI - Instituto Superior de Desenho Industrial - escalados especialmente para me assessorar nesta intervenção urbana. $\mathrm{Na}$ deriva pela cidade, a surpresa...

Fig 10. Phantasmata (Havana 2015)

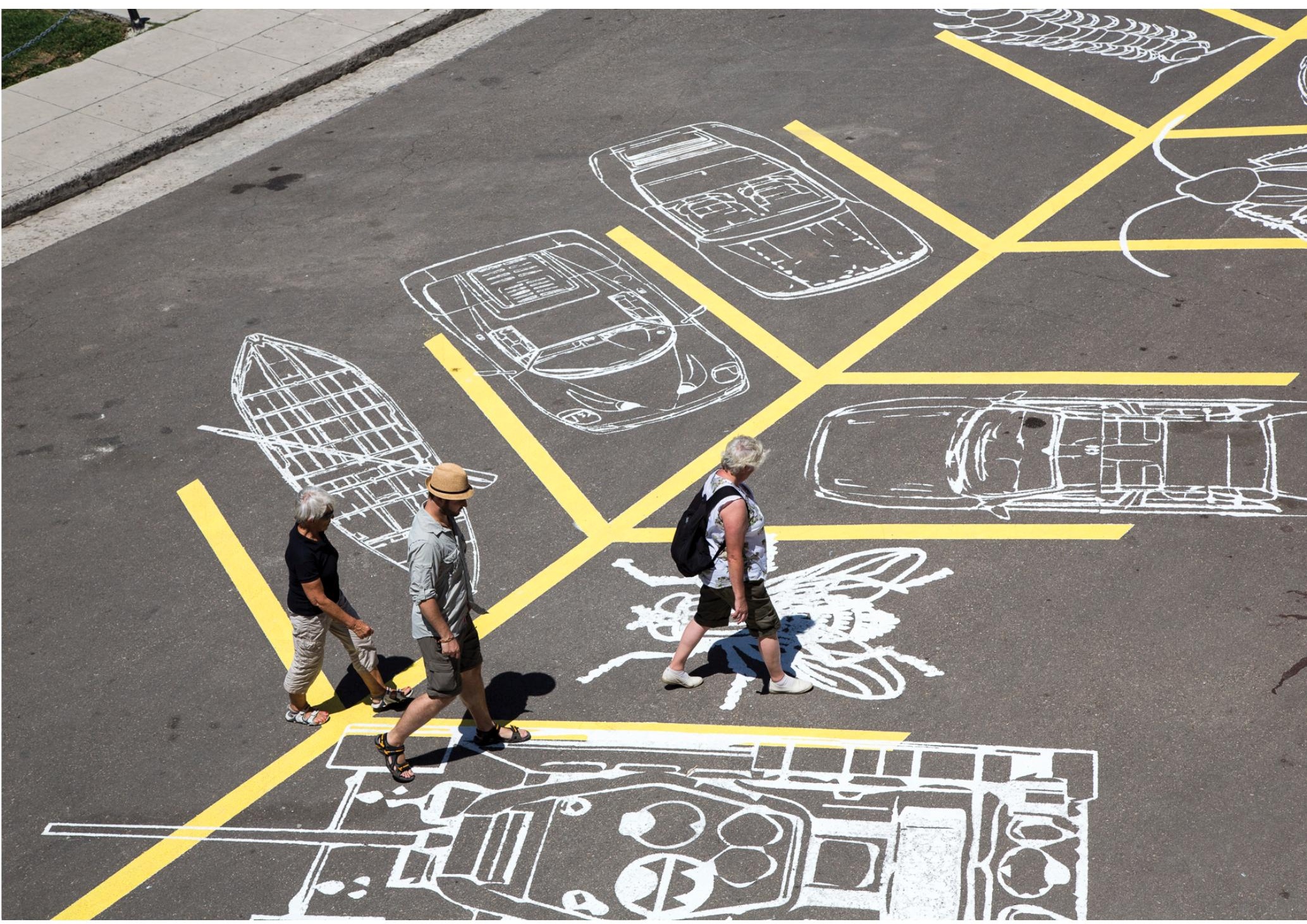

DATJournal v.4 n.3 2019 
para as novas calçadas. Mais ambicioso ainda é o plano profissionalizante acoplado ao projeto, para que os moradores tenham acesso e instrumentos para uma formação profissional especifica, focada em aprender a produzir e a colocar o tipo de lajota drenante - especialmente desenvolvida pela Politécnica, para controlar as águas das chuvas.

A mim como artista /autora que no inicio deste processo de envolvimento com aquelas comunidades queria tão somente levar um pouco de ordem e beleza aquelas áreas onde isto não existe, coube gradativamente ganhar a consciência de que o que tinha a fazer era chegar - sucintamente - à criação dos seis módulos das lajotas coloridas com que os moradores mesmos vão aprender a configurar seus motivos e, em termos mais gerais, exercer a coordenação de um projeto de arte pública cuja marca maior é o pertencimento implicado. A esperança é que o Nossa Calçada possa ajudar a resolver o descuido oficial generalizado para com a arte pública, pois para aqueles moradores convocados o mote vai ser: "as calçadas são nossas, nós mesmos fizemos e cuidamos".

Fig 16. Nossa Calçada
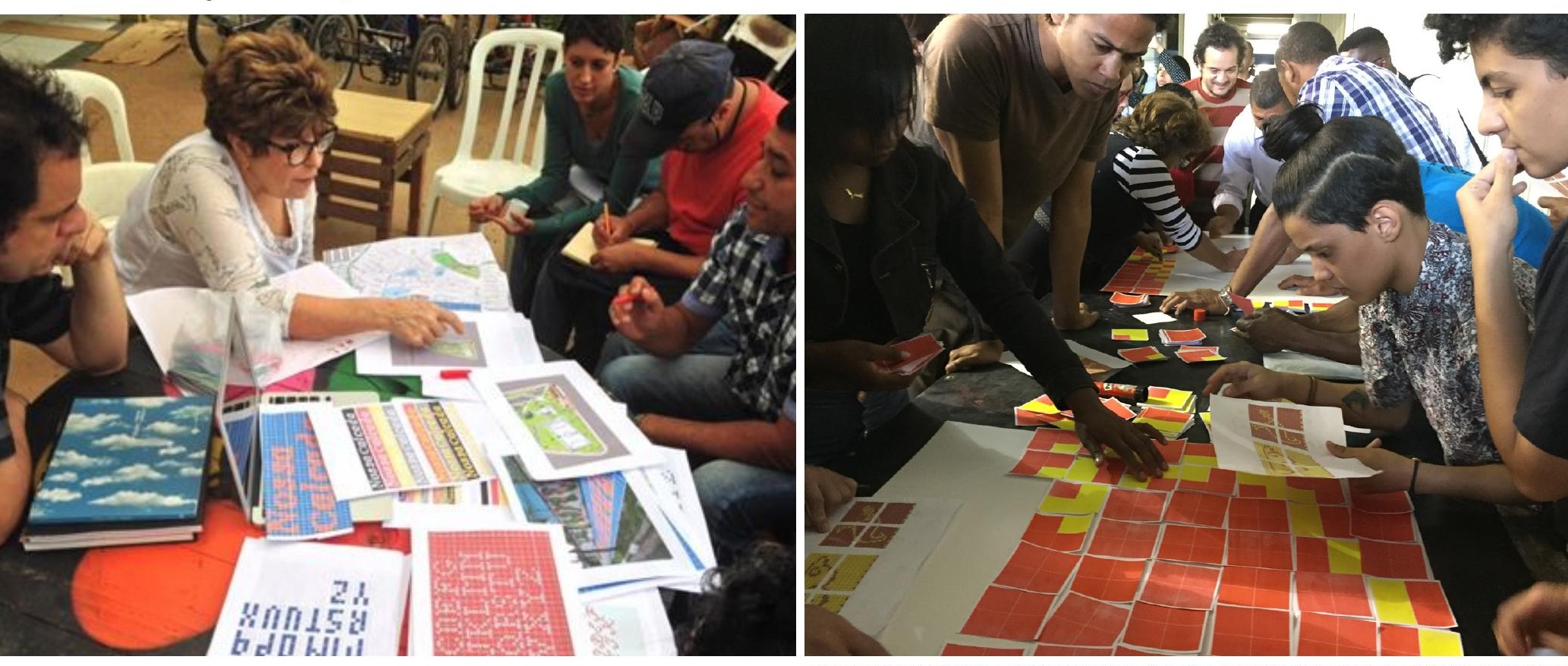
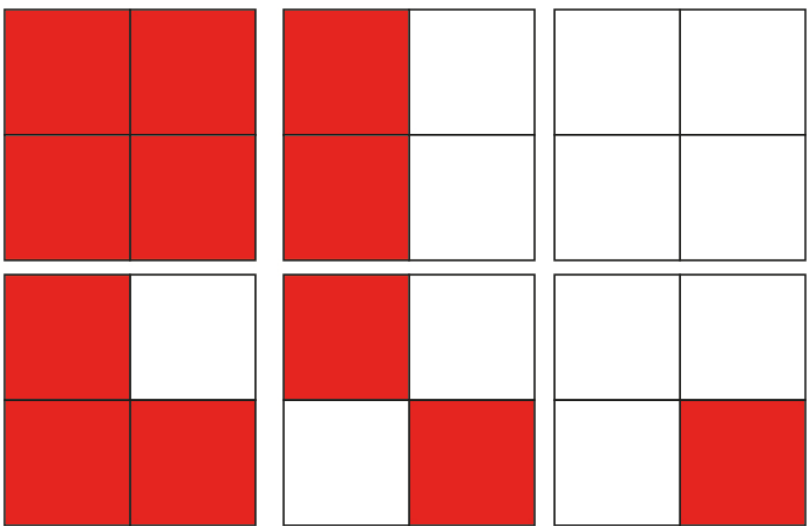

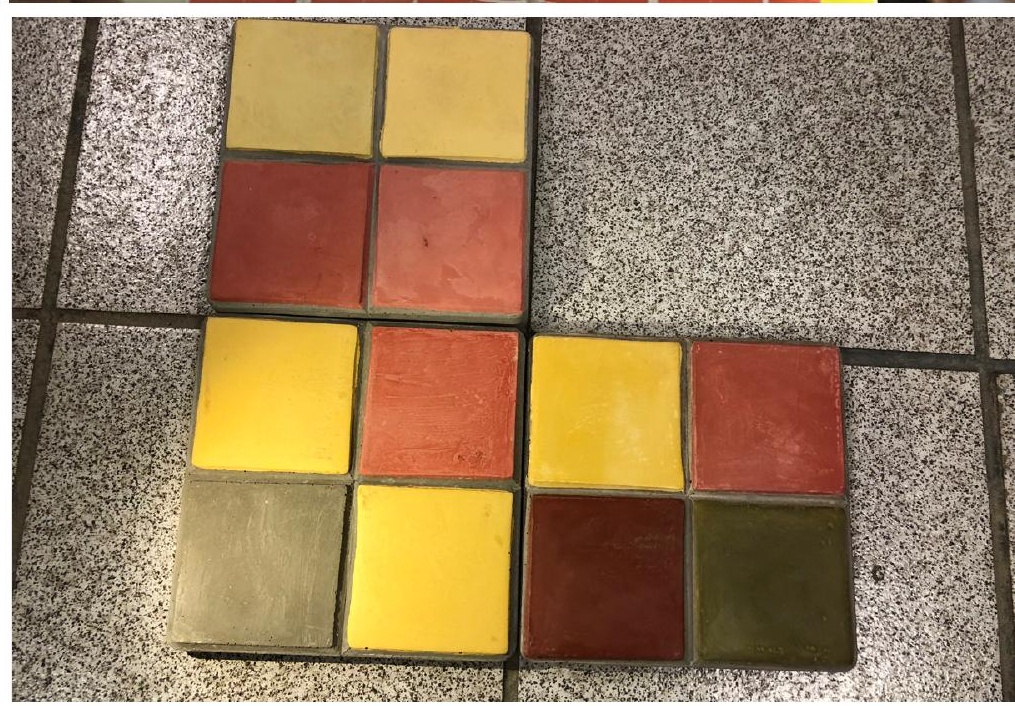




\section{Conclusão}

Ao longo desta fala disse diversas vezes que para o artista/autor é bem difícil aferir o grau de prazer - nesta altura até gostaria de substituir esta expressão por grau de transformação, ou melhor ainda, de contaminação - enquanto efeito que as imagens podem causar na recepção da arte, pois por mais que queira, o artista não tem qualquer controle sobre a fruição do outro... Entretanto, o mesmo artista está infalivelmente incluído na interpretação, pela simples intencionalidade embutida na obra.

Para concluir, queria assinalar que a maioria das obras que convoquei para esta apresentação já não existem mais, pela condição de efemeridade que as caracterizou. Apenas em alguns casos quando a memoria digital é estocada como matriz, elas guardam a possibilidade de repetição futura, em versões, desejavelmente renovadas. Fora isto, são pura documentação e memoria. Agradeço a oportunidade de puder repartir com este publico um pouco desta memória e de fazer essas considerações sobre as funções da arte.

\section{Bibliografia}

BARTHES, Roland. Prazer do Texto . São Paulo: Perspectiva, 2015.

SILVEIRA, Regina, Projeto Nossa Calçada. ZL Vortice Intervenções Urbanas - Laboratório (Dezembro, 7, 2015). Disponível em:, https://zlvortice.wordpress.com/2015/12/07/regina-silveira-projeto-nossa-calcada/ Acesso em: 25 ago. 2019.

SILVEIRA, Regina. (2016). Olhar o Percurso: depoimento de artista in Diálogos transdisciplinares: arte e pesquisa. (PRADO, Gilbertto; TAVARES, Monica; ARANTES, Priscila (Org.)). São Paulo : ECA/USP. p. 9-41. Disponível em: http://poeticasdigitais.net/assets/dialogostransdisciplinares2.pdf Acesso em: 25 ago. 2019. 